\title{
Constructing the Training Curriculum of Standardized Patients for OSCE Examination for Undergraduate Nursing Students in Shanxi Medical University
}

\author{
Jie Zheng1, Yuejuan Jing'2, Shujuan Wang2, Rui-Hua Jin³, Yuzhen Gao4* \\ ${ }^{1}$ Lecturer of the Graduate School, Shanxi Medical University, Taiyuan, China \\ ${ }^{2}$ Nurse of Department of Nephrology, The Second Hospital of Shanxi Medical University, Taiyuan, China \\ ${ }^{3}$ Deputy Vice-Chancellor of the Nursing School, Shanxi Medical University, Taiyuan, China \\ ${ }^{4}$ Head Nurse of Department of Cardiology, The Second Hospital of Shanxi Medical University, Taiyuan, China \\ Email: "yiqizouguo.happy@gmail.com
}

Received 1 December 2013; revised 27 January 2014; accepted 11 February 2014

Copyright (C) 2014 by authors and Scientific Research Publishing Inc.

This work is licensed under the Creative Commons Attribution International License (CC BY).

http://creativecommons.org/licenses/by/4.0/

$$
\text { (c) (i) Open Access }
$$

\begin{abstract}
Objective: The objective of this study is to construct the simulated patient training curriculum for OSCE examination for undergraduate nursing students and to explore the theoretical and practical foundation. Methods: To establish TSP training curriculum and SSP training curriculum, 30 experts were invited to finish the questionnaires which were proved by Delphi Method. Findings: We established the training curriculum of TSP and SSP, and set the weight of various curricula and teaching contents. Conclusions: The experts considered that the degree and importance of these two training curricula were comparable. This conclusion lays the foundation for applying these curricula to teaching practice and clinical practice, and enhancing the teaching outcome of undergraduate nursing students. Implications: This study provided a new way of assessing the clinic ability of nursing students.
\end{abstract}

\section{Keywords}

Students Nursing; Objective Structured Clinical Examination; Patient Simulation

\footnotetext{
${ }^{*}$ Corresponding author.
} 


\section{Introduction}

Objective structured clinical examination (OSCE) is an objective and standardized assessment way that was used in assessing the clinic ability of nursing students [1]-[3]. In 1968, Pr. Barrows reported to use simulated patients (SPs) in medical teaching and developed SP in department of neurology. Since then SP has become the standard practice of modern medical school teaching and has been used around the world [4]. SPs are healthy persons that simulate patients. They can be supervisors, instructors, teacher standardized patient (TSP) and student standardized patient (SSP) [5]. TSP is the teacher who has rich medical knowledge and clinical teaching experience and is the standardized patient and tests the students [6]. SSP is selected from the medical students who have some medical knowledge, and after strict training, is selected as standardized patient [7]. As an objective and effective educational resource, SP is a new method of practical teaching and assessment which meet modern teaching needs [6]. However, due to a directed relationship between the training quality and teaching quality, standard and effective training will be the focus in this area. In consideration of the differences between TSP and SSP in gaining professional knowledge and training, this study is designed to evaluate the comparativity of the training programs for TSP and SSP [8].

\section{Methods}

\subsection{Training Program}

\subsubsection{Design of SP Training Program}

Use the Delphi technique [9].

1) Setting up Research Team

There are one nursing professor and three nursing associate-professors in the research team, whose main task is to select experts, design tables, and data analysis.

2) Establishing Experts Group According to the Filtering Criteria

According to the purpose of the research subjects and Delphi method, we established the experts inclusion criteria: 1) with theoretical knowledge or practical experience in teaching simulation, be familiar with SP recruit and training; 2) Have worked 10 years or more in SP-related fields; 3) being able to offer comprehensive opinions, willing to support nursing research and answer questionnaires; 4) can promise to finish two rounds of consultation. After initial screening, we distributed 34 questionnaires and the recovery rate was $88 \%$. The basic information of experts is listed in Table 1.

3) Design Questionnaire

According to the principles of TSP and SSP training programs for nursing undergraduates, and after combining the research data of SP recruit and SP training, we designed the questionnaire which was divided into 4 parts: 1) A letter to experts, introducing the background of this study, explaining the aim and task and the importance of experts' participation, 2) Questionnaire, which is the preliminary designed training program. Each item is scored 1 to 5. Experts need to give comments according to its importance. 3) Basic information of experts: including age, working experience, education background, degree, job title, job duty, professional field, and contact information. 4) The questionnaire about experts' familiarity on this study.

In the process of preliminary designing, we did full data analysis and the filling explanation of questionnaire was accurate and intelligible [10]. Considering the differences between TSP and SSP in training goal and content, we designed the targeted training program.

In order to make sure that the questionnaire is reasonable and scientific, we did pre-survey and revised the defects. After careful analysis, expert coordination group finished the questionnaire.

\subsubsection{Questionnaire Distributed and Recovered}

There were 2 rounds of expert consultations in this study. We distributed the questionnaires to experts first by E-mail and we sorted and did some statistical analysis after recovering questionnaires. Then we added or deleted some knowledge points according to the selection principle which includes the mean of importance assignment $\geq 4.0, \mathrm{CV} \leq 0.25$, reference percent of full mark $\geq 10 \%$ and expert' suggestion. On this basis, we revised and made the second questionnaire sending to experts with summarized results.

\subsubsection{Statistical Analysis}

All analyses were performed using SPSS (version 13.0, SPSS Inc., Chicago, IL). In all instances, p-value less 
Table 1. Basic information of experts $(n=30)$.

\begin{tabular}{cccc}
\hline Item & & N & $\%$ \\
\hline Age & $\leq 44$ & 17 & 56.67 \\
& $45 \sim$ & 36.67 & 6.67 \\
Work experience & $>60$ & 11 & 13.33 \\
& $10-20$ & 2 & 63.33 \\
Degree & 21 - 30 & 4 & 23.33 \\
& $>30$ & 19 & 40.00 \\
Job title & Bachelor & 7 & 43.33 \\
& Master & 12 & 16.67 \\
Duty & Doctor & 13 & 40.00 \\
& Full professor & 5 & 60.00 \\
& Associate professor & 12 & 13.33 \\
& Dean or vice-dean & 18 & 60.00 \\
& Director or Vice Director in nursing field & 4 & 16.67 \\
& Head of nursing department & 18 & 10.00 \\
& Science of nursing education & 5 & 43.33 \\
& Science of Nursing Management & 3 & 30.00 \\
& Clinical care & 13 & 13.33 \\
& Psience research in nursing & 9 & 6.67 \\
& Multi-fields & 4 & 3.33 \\
& & 2 & 3.33 \\
\hline
\end{tabular}

than 0.05 are considered significant. All reported p-values are two tailed.

Descriptive analysis was expressed by frequency, component ratio, approve rating; expert positivity coefficient was expressed by effective questionnaire returns-ratio and the percent of expert offer a proposal; the authority of experts are analyzed by three factors including the academic level of experts, criterion, and familiarity; the consistency of expert opinions was expressed by each item grades; coordination degree of expert opinions was expressed by variable coefficient and expert coordination coefficient.

\section{Results and Discussions}

\subsection{TSP Training Program (See in Table 2)}

Table 2. TSP Training syllabus assignment $M \pm S$, CV, full score ratio $(n=30)$.

\begin{tabular}{|c|c|c|c|}
\hline Training content & $\bar{X} \pm \mathrm{S}$ & $\mathrm{CV}$ & Full score ratio \\
\hline Lesson 1 TSP related knowledge & $4.65 \pm 0.483$ & 0.104 & 0.6563 \\
\hline Teaching content 1 concept of TSP & $4.40 \pm 0.712$ & 0.162 & 0.5313 \\
\hline Teaching content 2 aim of TSP & $4.18 \pm 0.780$ & 0.186 & 0.4063 \\
\hline Teaching content 3 function of TSP & $4.50 \pm 0.622$ & 0.138 & 0.5625 \\
\hline Teaching content 4 program of taking history and health education & $4.68 \pm 0.471$ & 0.101 & 0.6875 \\
\hline Teaching content 5 the necessary quality and knowledge for TSP & $4.62 \pm 0.492$ & 0.106 & 0.6250 \\
\hline Lesson 2 OSCE related knowledge & $4.34 \pm 0.602$ & 0.139 & 0.4063 \\
\hline Teaching content 1 concept of OSCE & $4.37 \pm 0.702$ & 0.162 & 0.500 \\
\hline Teaching content 2 practical significance of OSCE in nursing education & $4.21 \pm 0.608$ & 0.144 & 0.313 \\
\hline Teaching content 3 the relationship between OSCE and TSP & $4.15 \pm 0.767$ & 0.184 & 0.375 \\
\hline Teaching content 4 the design of OSCE examination hall & $4.37 \pm 0.609$ & 0.139 & 0.438 \\
\hline
\end{tabular}




\section{Continued}

Lesson 3 introduction of taking history and heath education

Teaching content 1 concept of taking history

Teaching content 2 technique of taking history

Teaching content 3 major impact factors for taking history

Teaching content 4 concept of heath education

Teaching content 5 technique of health education

Teaching content 6 major impact factors for heath education

\section{Lesson 4 patients' role behavior and mental activity}

Teaching content 1 illness behavior, sick role and role adaption

Teaching content 2 patients’ need

Teaching content 3 general psychological changes and psychological problems for patients

Teaching content 4 characteristic of psychological activity for patients

\section{Lesson 5 important disease related knowledge in OSCE}

Teaching content 1 related knowledge that TSP need to grasp: medical history, clinical symptoms, physical sign, inspection results

Teaching content 2 the content of taking history and education that TSP should grasp

Teaching content 3 patients’ psychological states and basic need that TSP should grasp

\section{Lesson 6 TSP how to act patients and teachers dual roles}

Teaching content 1 provide case content correctly

Teaching content 2 full in take history table and health education table accurately

Teaching content 3 introduce standard of scoring to nursing students

Teaching content 4 feedback of assessment

\section{Lesson 7 practice}

Teaching content 1 TSP related knowledge

Teaching content 2 OSCE related knowledge

Teaching content 3 taking history and health education related knowledge

Teaching content 4 patients' role behavior and mental activity

Teaching content 5 important disease related knowledge in OSCE

Teaching content 6 TSP how to act patients and teachers dual roles

\begin{tabular}{|c|c|c|}
\hline $4.75 \pm 0.439$ & 0.092 & 0.750 \\
\hline $4.71 \pm 0.456$ & 0.096 & 0.718 \\
\hline $4.78 \pm 0.420$ & 0.087 & 0.781 \\
\hline $4.34 \pm 0.653$ & 0.150 & 0.437 \\
\hline $4.65 \pm 0.545$ & 0.117 & 0.687 \\
\hline $4.68 \pm 0.470$ & 0.100 & 0.687 \\
\hline $4.28 \pm 0.683$ & 0.159 & 0.375 \\
\hline $4.53 \pm 0.507$ & 0.112 & 0.531 \\
\hline $4.46 \pm 0.567$ & 0.126 & 0.500 \\
\hline $4.50 \pm 0.672$ & 0.149 & 0.593 \\
\hline $4.59 \pm 0.499$ & 0.108 & 0.593 \\
\hline $4.46 \pm 0.621$ & 0.139 & 0.531 \\
\hline $4.68 \pm 0.535$ & 0.114 & 0.718 \\
\hline $4.62 \pm 0.609$ & 0.131 & 0.687 \\
\hline $4.71 \pm 0.581$ & 0.123 & 0.781 \\
\hline $4.62 \pm 0.553$ & 0.119 & 0.656 \\
\hline $4.78 \pm 0.490$ & 0.102 & 0.812 \\
\hline $4.78 \pm 0.490$ & 0.102 & 0.812 \\
\hline $4.78 \pm 0.420$ & 0.087 & 0.781 \\
\hline $4.56 \pm 0.564$ & 0.123 & 0.593 \\
\hline $4.81 \pm 0.396$ & 0.082 & 0.812 \\
\hline $4.68 \pm 0.470$ & 0.100 & 0.687 \\
\hline $4.62 \pm 0.609$ & 0.131 & 0.687 \\
\hline $4.65 \pm 0.545$ & 0.117 & 0.687 \\
\hline $4.78 \pm 0.420$ & 0.087 & 0.781 \\
\hline $4.56 \pm 0.564$ & 0.123 & 0.593 \\
\hline $4.56 \pm 0.759$ & 0.166 & 0.718 \\
\hline $4.81 \pm 0.396$ & 0.082 & 0.812 \\
\hline
\end{tabular}

\subsection{Training Syllabus of SSP See in Table 3}

Table 3. TSP Training syllabus course weights order.

\begin{tabular}{lcc}
\hline \multicolumn{1}{c}{ Course Name } & Course weight & Curriculum places \\
\hline F TSP How to play dual roles of teacher and patients & 0.128 \\
C Special care and summary of health education & 0.127 \\
E Relevant knowledge of the disease in all subjects of the undergraduate nursing & 0.126 \\
students OSCE test & 0.126 \\
G Overall practice class & 0.126 \\
H Assessment & 0.125 \\
A Relevant knowledge of TSP & 3 \\
D The role behavior and psychological activity of patients & 0.122 \\
B Relevant knowledge of OSCE & 0.117 \\
\hline
\end{tabular}




\subsection{Consulting Results of Delphi Method}

Delphi was used to determine weights of indicators at all levels. Using Questionnaire to describe classification of indicators at various levels and connotation and relative importance of various entries, the experts gave corresponding suggestions, and the evaluation index that they believe should increase or adjust. Ask an expert to judge the importance of primary index in the index system and the importance of the secondary index at the corresponding level index and suitability, and according to determine each index and its weights. Two rounds of back-to-back consultation were conducted. In this paper, in order to illustrate its reliability, we adopted the method of calculating the degree of consistency between evaluators to reflect the equality of the assessment system. Test results show that the internal consistency Cronbach alpha is 0.90 , content validity was 0.83 . After the investigation, the author did the reliability analysis to each survey, inherent reliability coefficient of each survey results are more than 0.8 .

\subsection{The Design Results of Training Syllabus}

Tables 2 and 4 show that in the SP training curriculum, the outline assignment mean is between $4.40-4.87$, all is more than 4.0; coefficient of variation is $0.071-0.130$, all is less than 0.25 , full score ratio is $0.433-0.867$, the result shows that the expert assignment fluctuations is small. Therefore the coordination of experts' advice is conducive to form SP training outline of undergraduate nursing students in the OSCE. After two rounds of consultation using Delphi, training curriculum, the structure is more stable. The experts' opinion on the expression of the assignment, the recognition rate etc. tend to be more consistent.

Analysis of Table 3 shows that the weight of the TSP training syllabus reflects the following characteristics: the weight gap between the overall design of the eight courses is not very big, the weight gap of the teaching content of each training course is not big; Structure of TSP training syllabus is reasonable, comprehensively reflects the training objectives from four angles including the goal, teaching content, teaching time, and teaching methods; How the dual roles of teacher and patient is played is the key for TSP training, and this play a decisive role for clinical nursing teachers to be a qualified TSP.

Analysis of Table 5 shows that the first of the SSP training syllabus' the weight is "the related knowledge of SSP and related knowledge of common disease in all the subjects". This outline was mainly aimed at SSP of undergraduate nursing students in the OSCE. To understand and master the relevant knowledge of the SSP is the basis of being SP. Solid knowledge of the common diseases in all areas are the prerequisite to be good SP; Secondly, the role of SP is to undertake the dual role of patient and examiner. Therefore, how the SSP play the dual role is the most important in the course design. Thirdly, the clinical practice and the overall connection are important. After accepting the experts' opinions, we added the clinical practice in the design of curriculum in the second round of the outline in order to strengthen the knowledge of the SSP on the disease. Overall, the weight of eight courses were similar, which also suggests that all the courses are very important, the content of undergraduate nursing students' SSP training outline in the OSCE is very necessary.

The essence of the OSCE is the integration of students' knowledge and skills into a professional practice [11]. Experimental study by Critchley et al. [12] and Khattab et al. [13] showed that SP was superior to the traditional test methods in the clinical ability test. The application of student SP for nursing assessment and health education in their research, effect of medical history collection are similar, The students' interest in learning and clinical skills were improved. At the same time, the SP method is good for conducting universal training and examination and reducing subjectivity. Therefore, this training method is feasible practically.

\section{Conclusion}

Facing the increased demand for nursing staff in the society and the relative lack of clinical teaching resources, application of standardized patient (SP) has shown that it has unique advantages and broad prospects for development. Under the current economic conditions of China, and as the less than optimal capital investment in collage education, training of standardized patients is an innovative and beneficial attempt.

\section{Acknowledgements}

The work was undertaken at The Graduate School, Shanxi Medical University, and was supported financially by soft science research resource funded project of Shanxi province Department of Science and Technology and 
Table 4. Training outline of SSP assignment mean \pm Standard deviation, variable coefficient, Full score ratio $(\mathrm{n}=30)$.

\begin{tabular}{|c|c|c|c|}
\hline Training content & $\bar{X} \pm \mathrm{S}$ & $\mathrm{CV}$ & Full score ratio \\
\hline Lesson One Relevant knowledge of SSP & $4.87 \pm 0.346$ & 0.071 & 0.867 \\
\hline The teaching content 1 Concept of SSP & $4.60 \pm 0.498$ & 0.108 & 0.600 \\
\hline The teaching content 2 The purpose of cultivating the SSP (necessity) & $4.70 \pm 0.466$ & 0.099 & 0.700 \\
\hline The teaching content 3 Play of he processes of the special care and health education of SSP & $4.70 \pm 0.466$ & 0.099 & 0.700 \\
\hline Lesson two Relevant knowledge of OSCE & $4.63 \pm 0.556$ & 0.120 & 0.667 \\
\hline The teaching content 1 Concept of OSCE & $4.53 \pm 0.571$ & 0.126 & 0.567 \\
\hline The teaching content 2 The design of the OSCE test stand & $4.63 \pm 0.556$ & 0.120 & 0.667 \\
\hline The teaching content 3 The relationship between OSCE and SSP & $4.70 \pm 0.4796$ & 0.103 & 0.667 \\
\hline Lesson three nursing assessment and summary of health education & $4.80 \pm 0.407$ & 0.085 & 0.800 \\
\hline The teaching content 1 The contents of nursing assessment & $4.50 \pm 0.572$ & 0.127 & 0.533 \\
\hline The teaching content 2 Nursing assessment skills & $4.70 \pm 0.535$ & 0.114 & 0.733 \\
\hline The teaching content 3 The main factors influencing the nursing assessment & $4.53 \pm 0.507$ & 0.112 & 0.533 \\
\hline The teaching content 4 The content of health education & $4.40 \pm 0.563$ & 0.128 & 0.433 \\
\hline The teaching content 5 Health education skills & $4.60 \pm 0.563$ & 0.122 & 0.633 \\
\hline The teaching content 6 The influence factors of clinical nursing health education & $4.57 \pm 0.568$ & 0.124 & 0.600 \\
\hline Lesson four The role behavior and psychological activity of patient & $4.63 \pm 0.490$ & 0.106 & 0.633 \\
\hline The teaching content 1 Role and role adaptation of Patients & $4.57 \pm 0.568$ & 0.124 & 0.600 \\
\hline The teaching content 2 The needs of the patient & $4.67 \pm 0.547$ & 0.117 & 0.700 \\
\hline $\begin{array}{l}\text { The teaching content } 3 \text { General psychological change and psychological problems of } \\
\text { Patients with }\end{array}$ & $4.53 \pm 0.571$ & 0.126 & 0.567 \\
\hline The teaching content 4 Psychological activity of Patient's & $4.53 \pm 0.571$ & 0.126 & 0.567 \\
\hline Lesson five Related knowledge of common diseases in all the subjects & $4.87 \pm 0.346$ & 0.071 & 0.867 \\
\hline The teaching content 1 The related knowledge of key disease in all the subjects & $4.80 \pm 0.407$ & 0.085 & 0.800 \\
\hline $\begin{array}{l}\text { The teaching content } 2 \text { Main points of nursing assessment and health education content of } \\
\text { Priority diseases in all the subjects }\end{array}$ & $4.80 \pm 0.407$ & 0.085 & 0.800 \\
\hline $\begin{array}{l}\text { The teaching content } 3 \text { Psychological state and basic need of the patient's with key disease } \\
\text { in all the subjects }\end{array}$ & $4.70 \pm 0.466$ & 0.099 & 0.700 \\
\hline Lesson six SSP How to play dual roles in patients and grade giver & $4.83 \pm 0.379$ & 0.078 & 0.833 \\
\hline The teaching content 1 How to provide cases correctly & $4.73 \pm 0.583$ & 0.123 & 0.800 \\
\hline $\begin{array}{l}\text { The teaching content } 2 \text { How to accurately fill in the table of nursing care and assessment } \\
\text { of health education methods }\end{array}$ & $4.77 \pm 0.430$ & 0.090 & 0.767 \\
\hline The teaching content 3 How to explain to a student nurse grading & $4.67 \pm 0.547$ & 0.117 & 0.700 \\
\hline The teaching content 4 How to feedback & $4.67 \pm 0.606$ & 0.130 & 0.733 \\
\hline Lesson seven Clinical practice & $4.80 \pm 0.407$ & 0.085 & 0.800 \\
\hline Lesson eight overall practice & $4.67 \pm 0.479$ & 0.102 & 0.667 \\
\hline
\end{tabular}

Table 5. SSP Training syllabus course weights order.

\begin{tabular}{lcc}
\multicolumn{1}{c}{ The training content } & Course weight & Curriculum places \\
\hline A The related knowledge of SSP & 0.128 & 0.128 \\
E Related knowledge common diseases in all the subjects & 0.127 & 1 \\
F SSP How to play dual roles in patients and grade giver & 0.126 \\
G Clinical practice & 0.126 \\
H Overall practice & 0.123 \\
C Nursing assessment and Summary of health education & 0.122 \\
B The related knowledge of OSCE & 0.122 \\
D The role behavior and psychological activity of patient & 3 \\
\hline
\end{tabular}


teaching reform funded project of Shanxi Medical University. The assisting funds are 10,000 and 30,000 RMB respectively.

\section{Contributors}

Zheng Jie and Gao Yuzhen was involved in the conception and design of the study. Jing Yuejuan, Wang Shujuan prepared and cleaned the data and Zheng Jie did the statistical analysis and wrote the first draft. All authors had full access to all of the data (including statistical reports and tables) in the study and can take responsibility for the integrity of the data and the accuracy of the data analysis.

\section{References}

[1] Harden, R.M. and Stevenson, M. (1975) Assessment of Clinical Competence Using Objective Structured Examination. British Medicine Journal, 1, 447-451. http://dx.doi.org/10.1136/bmj.1.5955.447

[2] Merrick, H.W., Nowacek, G., Boyer, J., et al. (2000) Comparison of the Objective Structured Clinical Examination with the Performance of Third-Year Medical Students in Surgery. American Journal of Surgery, 179, 286-288. http://dx.doi.org/10.1016/S0002-9610(00)00340-8

[3] Zhong, Y.J., Wang, M. and Li, Q. (2009) Analyze the Development of Standardized Patient Teaching in China by Literature Renew in 10 Years. Chinese Journal of Nursing, 44, 259-260.

[4] Barrows, H.S. and Abrahamson, S. (1964) The Programmed Patient: A Technique for Appraising Student Performance in Clinical Neurology. Journal of Medical Education, 39, 802-805.

[5] Stillman, P.L. (1992) A New Program to Enhance the Teaching and Assessment of Clinical Skill in the People's Republic of China. Academic Medicine, 67, 495-499. http://dx.doi.org/10.1097/00001888-199208000-00002

[6] Xin, P., Ruihua, J. and Jie, Z. (2008) Cognition and Thinking on Teaching Model of Teacher Standardized Patients. Chinese General Research, 6, 3376-3377.

[7] Brown, A., Anderson, D. and Szedip, H.M. (2003) Using Standardized Patients to Teach Disease Management Skills to Preclinical Students: A Pilot Project. Teach Leach Learn Medicine, 15, 84-87.

[8] AAMC (1998) Emerging Trends in the Use of Standardized Patients. Contemporary Issues in Medical Education.

[9] Felicity, H. and Sinead, K. (2000) Research Guidelines for the Delphi Survey Technique. Journal of Advanced Nursering, 32, 1008-1015.

[10] Qiu, Y.F. (2007) A Preliminary Study on Evaluation Index System of Empathy Ability of Clinical Nursing Staff. Chinese Nursing Research, 21, 3072-3074.

[11] Bartfay, W.J., Rombough, R., Howse, E., et al. (2004) The OSCE Approach in Nursing Education: Objective Structured Clinical Examinations Can Be Effective Vehicles for Nursing Education and Practice by Promoting the Mastery of Clinical Skills and Decision-Making in Controlled and Safe Learning Environment. The Canada Nurse, 2004, 18-32.

[12] Critchley, L.A., Short, T.G., Buckley, T., et al. (1995) An Adaptation of the Objective Structured Clinical Examination to a Final Year Medical Student Course in Anaesthesia and Intensive Care. Anaesthesia, 50, 354-358. http://dx.doi.org/10.1111/j.1365-2044.1995.tb04617.x

[13] Khattab, A.D. and Rawlin, G.S.B. (2001) Assessing Nurse Practitioner Students Using a Modified Objective Structured Clinical Examination. Nursering Education Today, 21, 541-550. http://dx.doi.org/10.1054/nedt.2001.0590 